\title{
Application of a multiple-trait, multiple-country genetic evaluation model for female fertility traits
}

\author{
M. A. Nilforooshan, ${ }^{\star 1}$ J. H. Jakobsen, ${ }^{\star} †$ W. F. Fikse, ${ }^{\star}$ B. Berglund, ${ }^{\star}$ and H. Jorjani ${ }^{\star} \dagger$ \\ *Department of Animal Breeding and Genetics, Swedish University of Agricultural Sciences, 75007 Uppsala, Sweden \\ †Interbull Centre, 75007 Uppsala, Sweden
}

\begin{abstract}
The need to implement a method that can handle multiple traits per country in international genetic evaluations is evident. Today, many countries have implemented multiple-trait national genetic evaluations and they may expect to have their traits simultaneously analyzed in international genetic evaluations. Traits from the same country are residually correlated and the method currently in use, single-trait multiple across-country evaluation (ST-MACE), cannot handle nonzero residual correlations. Therefore, multiple-trait, multiple across-country evaluation (MT-MACE) was proposed to handle several traits from the same country simultaneously. To test the robustness of MT-MACE on real data, female fertility was chosen as a complex trait with low heritability. Data from 7 Holstein populations, 3 with 2 traits and 4 with 1 trait, were used. The differences in the estimated genetic correlations by MT-MACE and the single ST-MACE analysis (average absolute deviation of 0.064 ) were due to the bias of considering several traits from the same country in the ST-MACE analysis. However, the differences between the estimated genetic correlations by MT-MACE and multiple ST-MACE analyses avoiding more than one trait per country in each analysis (average absolute deviation of 0.066 ) were due to the lack of analysis of the correlated traits from the same country together and using the reported within-country genetic correlations. Applying MT-MACE resulted in reliability gain in international genetic evaluations, which was different from trait to trait and from bull to bull. The average reliability gain by MT-MACE over ST-MACE was 3.0 points for domestic bulls and 6.3 points for foreign bulls. Even countries with 1 trait benefited from the joint analysis of traits from the 2-trait countries. Another superiority of MT-MACE over ST-MACE is that the bulls that do not have national genetic evaluation for some traits from multiple trait countries will receive
\end{abstract}

Received May 14, 2010.

Accepted August 20, 2010.

${ }^{1}$ Corresponding author: Mohammad.Nilforooshan@hgen.slu.se international genetic evaluations for those traits. Rank correlations were high between ST-MACE and MTMACE when considering all bulls. However, the situation was different for the top 100 bulls. Simultaneous analysis of traits from the same country affected bull ranks, especially for top 100 bulls. Multi-trait MACE is a recommendable and robust method for international genetic evaluations and is appropriate for handling multiple traits per country, which can increase the reliability of international genetic evaluations.

Key words: multiple across-country evaluation, genetic correlation, reliability, female fertility

\section{INTRODUCTION}

International genetic evaluation of dairy bulls started with two-country comparisons using conversion equations considering unity genetic correlations between countries (IDF, 1981; Goddard, 1985; Wilmink et al., 1986). Because of the shortcomings of conversion equations (e.g., ignoring genotype by environment interaction; Banos and Sigurdsson, 1996), those were replaced by the method currently designated as single-trait, multiple across country evaluation (ST-MACE; Schaeffer, 1994). This method is capable of analyzing 1 trait per country, taking into consideration the genetic correlations less than unity among countries. The ST-MACE method assumes that traits from different countries have been measured on different daughter groups and therefore, residual covariance is not modeled.

Many countries are now using multiple-trait national genetic evaluation models and expect the international genetic evaluations to consider those traits simultaneously. Analyzing multiple traits per country in international genetic evaluations using the ST-MACE method would lead to bias, because of ignoring residual covariances among the traits analyzed in the same country and overcorrection for the genetic correlations among the traits.

An appropriate way of handling multiple traits per country in international genetic evaluations became possible with the method currently designated as multiple-trait, multiple across-country evaluation (MT- 
MACE; Schaeffer, 2001; Sullivan and Wilton, 2001). Integrated parts of MT-MACE were the derivation of multiple-trait deregression and multiple-trait effective daughter contribution (EDC; Liu et al., 2004; Sullivan et al., 2005). The first formulation of MT-MACE (Schaeffer, 2001) included block residuals based on the number of daughters in different traits as weighting factors. The use of EDC (Fikse and Banos, 2001; Liu et al., 2004; Sullivan et al., 2004) has been preferred over using the number of daughters. However, deriving the inverse of the block residuals for large data sets or approximation of the diagonal elements of the inverse matrix using multiple-trait block EDC values $\left(\mathbf{E D C}_{\mathrm{MTr}}\right.$; Liu et al., 2004; Tarrés et al., 2007) has not been feasible for all Interbull participating countries. Sullivan and Wilton (2001) introduced an alternative method for converting single-trait scalar EDC values $\left(\mathbf{E D C}_{\mathbf{S T}}\right)$ to multiple-trait scalar EDC values (ED$\left.\mathbf{C}_{\mathrm{MTi}}\right)$. Multiple-trait deregressed national predicted genetic merits (MTi-DPGM), which are equivalent to nationally independent traits, are computed from national predicted genetic merits (NPGM) and ED$\mathrm{C}_{\mathrm{MTi}}$. Then, it is possible to analyze the traits using the ST-MACE method.

Multi-trait MACE has been tested on simulated data (Sullivan et al., 2005; Tarrés et al., 2007) as well as on field data (Liu et al., 2004; Jorjani, 2006; Mark and Sullivan, 2006). Sullivan et al. (2005) studied various methods for international comparisons of dairy bulls on simulated data for 2 exporting and 2 importing counties, with 3 traits (lactations) from each. The error of prediction was equally low for both MT-MACE methods with block residuals (MTr; Schaeffer, 2001) and scalar residuals (MTi; Sullivan and Wilton, 2001). They concluded that MT-MACE methods were preferable over ST-MACE because of their relatively lower error of prediction and the benefits of having more than one trait per country in international genetic evaluations. Liu et al. (2004) developed a method for approximating multiple-trait daughter yield deviation and the associated reliabilities based on nationally calculated $\mathrm{EDC}_{\mathrm{MTr}}$. The method was implemented in MT-MACE and verified using data on production traits from Germany and France (Liu et al., 2004), on female fertility data from Germany, Austria, and Luxembourg (Liu et al., 2008), and on simulated data (Tarrés et al., 2007), which gave approximate reliabilities equal to exact values.

Although MTr and MTi methods produce equally unbiased evaluations, the MTi method is easier to implement. Calculation of MTr values from block residuals is computationally more challenging and probably prohibitive for many national evaluation centers. In addition, the MTi method better suits the current required data structure for international genetic evaluations using the ST-MACE method. Mark and Sullivan (2006) applied the MTi implementation of the MT-MACE method to udder health data from 8 countries, including Denmark as the country with a multiple-trait national model including both SCC and clinical mastitis. They concluded that both ST-MACE and MTi yield unbiased and consistent predictions, and that MTi is a robust method for simultaneous international genetic evaluation of multiple traits per country. However, further investigation of the suitability of MTi for traits with lower heritability is needed, having more than one country with a multiple-trait national genetic evaluation and a mixture of various genetic and residual correlations among the traits.

The objective of this study was to apply the MTi implementation of the MT-MACE method to international genetic evaluation of female fertility traits within the current required data structure for international genetic evaluations. Female fertility was chosen to test the robustness of the MTi method because female fertility is a complex trait, generally lowly heritable, with several measurements correlated with a mixture of various genetic and residual correlation coefficients. Estimated genetic correlations, international predicted genetic merits (IPGM), and their reliabilities obtained from MTi were compared with the results obtained from 2 ways of handling the data (a single analysis containing all traits or multiple analyses with one trait per country in each analysis) with the ST-MACE method.

\section{MATERIALS AND METHODS}

Data from 7 countries or populations on 10 traits were extracted from the data submitted for the ST-MACE analyses performed in the Interbull (Uppsala, Sweden) test evaluation of September 2007. The following countries and traits were used (Table 1): days open from Belgium $\left(\mathbf{B E L}_{\mathrm{DO}}\right)$, calving to first insemination and first insemination to conception from Canada $\left(\mathbf{C A N} \mathbf{N}_{\mathbf{C F}}\right.$ and $\mathbf{C A N}_{\mathbf{F C}}$ ), calving to first insemination from Switzerland $\left(\mathbf{C H E}_{\mathbf{C F}}\right)$, calving to first insemination and first to last insemination from the joint GermanyAustria evaluation $\left(\mathbf{D E} \mathbf{U}_{\mathbf{C F}}\right.$ and $\left.\mathbf{D E} \mathbf{U}_{\mathbf{F L}}\right)$, calving to first insemination and first to last insemination from the joint Nordic evaluation (Denmark-Finland-Sweden; $\mathbf{D F S}_{\mathrm{CF}}$ and $\left.\mathbf{D F} \mathbf{S}_{\mathbf{F L}}\right)$, days open from Spain $\left(\mathbf{E S P}_{\mathbf{D O}}\right)$, and daughter pregnancy rate from the United States $\left(\mathbf{U S A}_{\mathbf{D P}}\right)$. Because Germany and Austria, as well as Denmark, Finland, and Sweden, have joint national genetic evaluations, their data were considered as 2 populations, as usual. The data were checked according to Interbull standard checks (Jakobsen and Hjerpe, 2006) and edited according to the rules of Interbull Code of 
Table 1. Heritabilities $\left(\mathrm{h}^{2}\right)$, number of bulls, average number of daughters (DTR) per bull, average number of sampling herds per bull (Herd/ bull), average estimated daughter contribution (EDC) per bull, average EDC per daughter per bull, and average reliability of the submitted national predicted genetic merits



${ }^{1} \mathrm{BEL}_{\mathrm{DO}}=$ days open from Belgium; $\mathrm{CAN}_{\mathrm{CF}}=$ calving to first insemination from Canada; $\mathrm{CAN}_{\mathrm{FC}}=$ first insemination to conception from Canada; $\mathrm{CHE}_{\mathrm{CF}}=$ calving to first insemination from Switzerland; $\mathrm{DEU}_{\mathrm{CF}}=$ calving to first insemination from the joint Germany-Austria evaluation; $\mathrm{DEU}_{\mathrm{FL}}=$ first to last insemination from the joint Germany-Austria evaluation; $\mathrm{DFS}_{\mathrm{CF}}=$ calving to first insemination from the joint


Spain; and $\mathrm{USA}_{\mathrm{DP}}=$ daughter pregnancy rate from the United States.

Practice (Interbull, 2008). The data from CAN, DEU, and DFS were from multiple-trait national genetic evaluations.

\section{ST-MACE}

This method was developed by Schaeffer (1994), and is in use by Interbull for international genetic evaluations. The method can be represented as

$$
\mathbf{y}_{i}=\mathbf{X}_{i} \mathbf{c}_{i}+\mathbf{Z}_{i} \mathbf{Q g} \mathbf{g}_{i}+\mathbf{Z}_{i} \mathbf{s}_{i}+\mathbf{e}_{i}
$$

where $\mathbf{y}_{i}$ is the vector of single-trait deregressed national predicted genetic merits (ST-DPGM), $\mathbf{c}_{i}$ is the vector of country means, $\mathbf{g}_{i}$ is the vector of random phantom parent groups, $\mathbf{s}_{i}$ is the vector of random sire genetic effects, and $\mathbf{e}_{i}$ is the vector of random residuals. The matrices $\mathbf{X}, \mathbf{Z}$, and $\mathbf{Q}$ relate observations to country means, sires to observations, and sires to phantom parent groups, respectively.

The mixed model equations for ST-MACE are

$$
\begin{gathered}
{\left[\begin{array}{ccc}
\mathbf{X}^{\prime} \mathbf{R}^{-1} \mathbf{X} & 0 & \mathbf{X}^{\prime} \mathbf{R}^{-1} \mathbf{Z} \\
0 & \mathbf{Q}^{\prime} \mathbf{A}^{-1} \mathbf{Q} \otimes \mathbf{G}^{-1} & -\mathbf{Q}^{\prime} \mathbf{A}^{-1} \otimes \mathbf{G}^{-1} \\
\mathbf{Z}^{\prime} \mathbf{R}^{-1} \mathbf{X} & -\mathbf{A}^{-1} \mathbf{Q} \otimes \mathbf{G}^{-1} & \mathbf{Z}^{\prime} \mathbf{R}^{-1} \mathbf{Z}+\mathbf{A}^{-1} \otimes \mathbf{G}^{-1}
\end{array}\right]} \\
{\left[\begin{array}{c}
\mathbf{c} \\
\mathbf{g} \\
\mathbf{Q g}+\mathbf{s}
\end{array}\right]=\left[\begin{array}{c}
\mathbf{X}^{\prime} \mathbf{R}^{-1} \mathbf{y} \\
0 \\
\mathbf{Z}^{\prime} \mathbf{R}^{-1} \mathbf{y}
\end{array}\right]}
\end{gathered}
$$

where $\mathbf{A}$ is the pedigree relationship matrix, $\mathbf{G}$ is the matrix of genetic (co)variances, and $\mathbf{R}$ is the diagonal matrix of residual variances:

$$
\mathbf{R}_{k}=V\left[\begin{array}{c}
\mathbf{e}_{1 k} \\
\mathbf{e}_{2 k} \\
\vdots \\
\mathbf{e}_{n k}
\end{array}\right]=\left[\begin{array}{cccc}
D_{1 k} \sigma_{e 1}^{2} & 0 & \cdots & 0 \\
0 & D_{2 k} \sigma_{e 2}^{2} & \cdots & 0 \\
\vdots & \vdots & \ddots & \vdots \\
0 & 0 & \cdots & D_{n k} \sigma_{e n}^{2}
\end{array}\right]
$$

where for bull $k$ and $n$ number of countries, $D_{i k}$ is the inverse of the $\mathrm{EDC}_{\mathrm{ST}}$ value, and $\sigma_{e i}^{2}$ is the residual variance of country $i$.

The data were analyzed in 3 steps. In the first step, NPGM were deregressed to ST-DPGM according to Jairath et al. (1998) using the nationally reported $\mathrm{EDC}_{\mathrm{ST}}$ values. In the second step, the genetic correlations and the sire variances were estimated using $\mathrm{EDC}_{\mathrm{ST}}$ and ST-DPGM values (see Figure 1). An expectation maximization-REML algorithm was used in this procedure (Klei and Weigel, 1998). In the third step, IPGM and their reliabilities were predicted based on the reported national heritabilities, $\mathrm{EDC}_{\mathrm{ST}}$ values, the estimated genetic correlations across countries, and sire variances (Klei and Weigel, 1998).

Repeated ST-MACE Analyses. One of the assumptions of the ST-MACE method is that only 1 trait per country should be included in the analysis. To fulfill this assumption, 8 different 7-variate ST-MACE analyses $(\mathbf{8 S T})$ were carried out, each including all singletrait countries (BEL, CHE, ESP, USA) plus different combinations of 1 trait from each 2-trait country (CAN, DEU, DFS). Genetic correlations were estimated and genetic merits and reliabilities were predicted on the scale of each trait in all runs. As a result of repeated analyses, each bull received 8 sets of evaluations on the scale of traits from single-trait countries and 4 sets of evaluations on the scale of traits from 2-trait countries. 


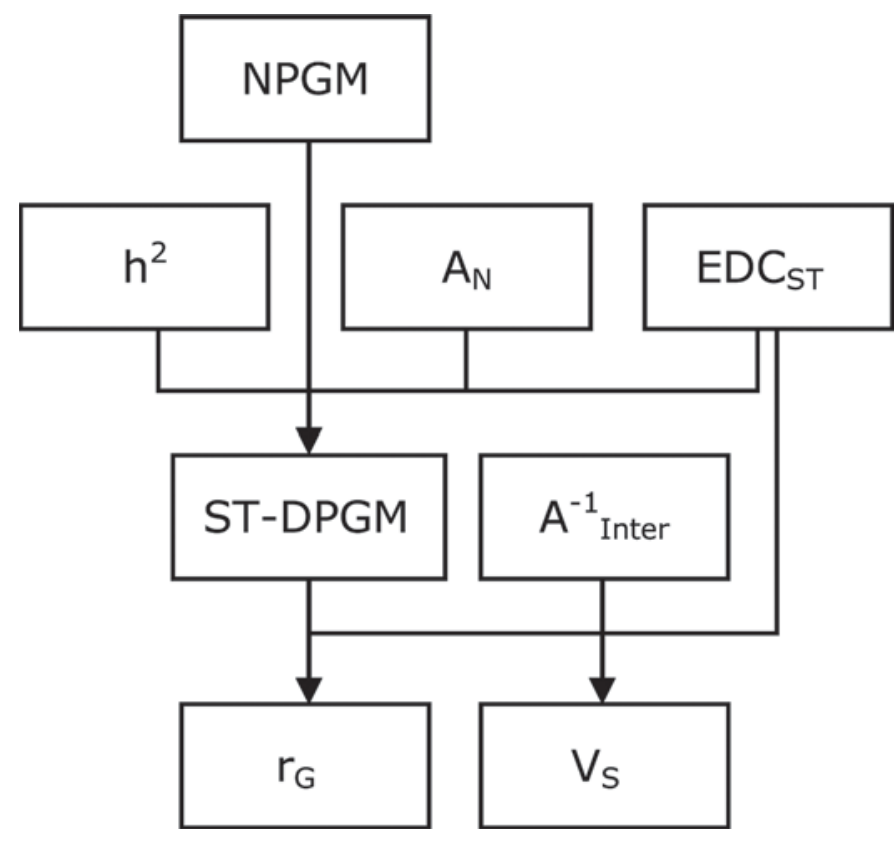

Figure 1. Single-trait, multiple across-country evaluation (STMACE) workflow for parameter estimation. NPGM = national predicted genetic merit; $\mathrm{h}^{2}=$ heritability; $\mathrm{A}_{\mathrm{N}}=$ national relationship matrix; $\mathrm{EDC}_{\mathrm{ST}}=$ single-trait effective daughter contribution (EDC); ST-DPGM = single-trait deregressed predicted genetic merits; $\mathrm{A}^{-1}$ Inter $=$ inverse of the international relationship matrix; $\mathrm{r}_{\mathrm{G}}=$ estimated genetic correlations; $\mathrm{V}_{\mathrm{S}}=$ estimated sire variances.

The averages of IPGM and reliabilities were used for each bull on the scale of each trait. No unique $10 \times$ 10 genetic correlation matrix was available to compare with the other strategies. Therefore, the eight $7 \times 7$ genetic correlation matrices were averaged, and the 3 empty cells for within-country genetic correlations were filled by the corresponding country-reported values (0.274 between CAN traits, 0.370 between DEU traits, and 0.409 between DFS traits). A weighted bending procedure (Jorjani et al., 2003) was used to make the derived $10 \times 10$ genetic correlation matrix positive definite. The inverse of the number of bulls within or between traits were used as weights.

Single ST-MACE Analysis. A single 10-variate ST-MACE analysis (1ST) including all traits was carried out. This analysis was conducted to assess the rate of bias caused by ignoring within-country residual correlations for multiple-trait nationally evaluated traits. Genetic correlations were estimated and genetic merits and reliabilities were predicted on the scale of each trait.

\section{MT-MACE (MTi)}

Applying the method of Sullivan and Wilton (2001), the reported scalar $\mathrm{EDC}_{\mathrm{ST}}$ values were converted to scalar $\mathrm{EDC}_{\mathrm{MTi}}$ values. The matrix of residual variances was built as for ST-MACE, using $\mathrm{EDC}_{\mathrm{MTi}}$ instead of $\mathrm{EDC}_{\mathrm{ST}}$. The NPGM values were also deregressed to MTi-DPGM. Using such $\mathrm{EDC}_{\mathrm{MTi}}$ and MTi-DPGM values, it was possible to analyze the traits as if those were any other trait from a different country.

The data were analyzed in 4 steps. In the first step, the scalar $\mathrm{EDC}_{\mathrm{ST}}$ values were converted to scalar ED$\mathrm{C}_{\mathrm{MTi}}$ values (Sullivan and Wilton, 2001). Because the reported $\mathrm{EDC}$ values from $\mathrm{DEU}$ were already $\mathrm{EDC}_{\mathrm{MTi}}$ values, those did not go through this step and DEU traits were considered as country-independent traits. In the second step, NPGM values were deregressed to MTi-DPGM according to Schaeffer (2001) using the scalar $\mathrm{EDC}_{\mathrm{MTi}}$ values from the previous step, national heritabilities, and within-country genetic correlations. In the third step, the genetic correlations and the sire variances were estimated using $\mathrm{EDC}_{\mathrm{MTi}}$ and MTi-DPGM values (see Figure 2). An expectation maximization-REML algorithm was used in this procedure (Klei and Weigel, 1998). In the fourth step, IPGM and their reliabilities were predicted based on the reported national heritabilities, $\mathrm{EDC}_{\mathrm{MTi}}$ values, the estimated genetic correlations, and sire variances (Klei and Weigel, 1998).

\section{Evaluations and Comparisons}

Genetic correlations were estimated by ST-MACE and MT-MACE (Figures 1 and 2, respectively). The estimations were computed based on the information on bulls born since 1970 and evaluated in at least one country plus the information on $3 / 4$ sib families with family members in more than one country. Afterward, sire variances were estimated repeating the previous steps up until the expectation maximization-REML estimation for bulls born since 1986. These data truncations were made to be consistent with Interbull routine evaluations. The IPGM and their reliabilities based on the scale of each trait were predicted for bulls born since 1986 from the corresponding DPGM and EDC values (ST or MTi), the country-reported parameters, the estimated genetic correlations, and sire variances.

The estimated genetic correlations by the ST-MACE method were compared with the correlations estimated by the MT-MACE method via deviations and average absolute deviations (AAD):

$$
A A D_{i}=\frac{1}{n} \sum_{j=1}^{n}\left|r_{i j}^{k S T}-r_{i j}^{M T i}\right|
$$

where $A A D_{i}$ is the average absolute deviation of the genetic correlations (for trait $i$ in the case of estimating 


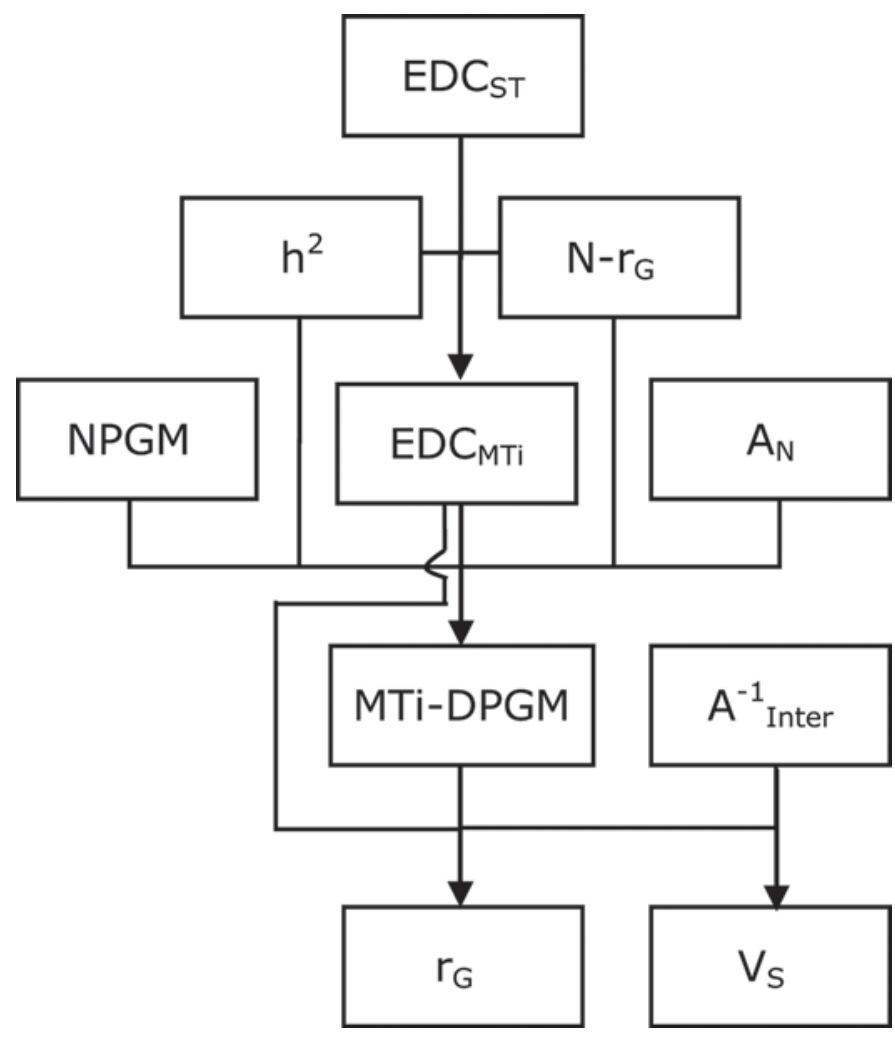

Figure 2. Multi-trait, multiple across-country evaluation (MT$\mathrm{MACE}$ ) workflow for parameter estimation. $\mathrm{EDC}_{\mathrm{ST}}=$ single-trait effective daughter contribution $(\mathrm{EDC}) ; \mathrm{h}^{2}=$ heritability; $\mathrm{N}-\mathrm{r}_{\mathrm{G}}=$ reported within-country genetic correlations; $\mathrm{NPGM}=$ national predicted genetic merit; $\mathrm{EDC}_{\mathrm{MTi}}=$ multiple trait $\mathrm{EDC} ; \mathrm{A}_{\mathrm{N}}=$ national relationship matrix; MTi-DPGM = multiple-trait deregressed predicted genetic merits; $\mathrm{A}_{\text {Inter }}^{-1}=$ inverse of the international relationship matrix; $\mathrm{r}_{\mathrm{G}}=$ estimated genetic correlations; $\mathrm{V}_{\mathrm{S}}=$ estimated sire variances.

$A A D$ by trait), $r_{i j}^{k S T}$ and $r_{i j}^{M T i}$ are the estimated genetic correlations $j$ by $\mathrm{kST}$ (where $k$ is the number of ST-MACE analyses, equal to 1 or 8 ) and MTi, and $n$ is the number of genetic correlations, equal to 45 (or equal to 9 for $A A D$ by trait).

Reliabilities obtained from the 3 methods were compared trait-wise by domestic and foreign bulls. To compare the IPGM computed by 1ST and 8ST with the IPGM computed by MTi, the former were regressed on the latter, by domestic and foreign bulls in each trait. Differences of intercept from zero and slope from 1 were considered as deviations from MTi. Finally, the rank correlations of all bulls among different methods as well as the number of bulls in common between the top 100 for each method were studied trait-wise.

\section{RESULTS AND DISCUSSION}

The countries with more bulls also had higher number of recorded daughters in more sampling herds, resulting in a relatively higher EDC value per bull (Table 1). The highest mean of EDC value per bull as well as the highest mean of EDC per daughter (DTR) per bull (EDC/ $\mathrm{DTR} /$ bull) was in $\mathrm{CAN}_{\mathrm{FC}}$ and $\mathrm{DFS}_{\mathrm{FL}}$. The heritability of the trait, the model of the national genetic evaluation, and the method of EDC calculation, which can be different across countries (Fikse and Banos, 2001; Liu et al., 2004; Sullivan et al., 2004) are the main reasons for the differences in EDC/DTR/bull across traits. As expected, the countries with a higher average number of daughters involved in the national evaluation of the bull had higher EDC values per bull but a relatively lower mean of EDC/DTR/bull. Thus, EDC/DTR/bull is an indicator of the average contribution that each daughter has in the EDC value of the bull. Higher EDC value associated with higher number of daughters, higher EDC/DTR/bull, and higher heritability have a major influence on reducing the prediction error variance for the bull and increasing its reliability.

The estimated genetic correlations by MTi ranged from 0.255 to 0.952 . The average of the estimated genetic correlations was 0.746 with the standard deviation of 0.175 (Table 2). The differences between MTi estimates of within-country genetic correlations and the country reported values (the reported values were $0.274,0.370$, and 0.409 for CAN, DEU, and DFS traits, respectively, compared with $0.323,0.809$, and 0.557 estimated by MTi) could be caused by the differences between the international sire model and the national animal models together with different population subsets used in the estimation of genetic correlations (bull NPGM vs. daughter performance).

The deviations of $8 \mathrm{ST}$ and $1 \mathrm{ST}$ genetic correlation matrices from the MTi genetic correlation matrix (Table 2) are presented in Table 3 . The estimated genetic correlations by MTi and 8ST were not very different $(\mathrm{AAD}=0.066)$ and the estimated genetic correlations by $8 \mathrm{ST}$ were on average 0.053 lower. It was expected that 8ST genetic correlations were not biased, and the observed differences between 8ST and MTi genetic correlations may be due to the lack of benefit from simultaneous analysis of traits from the same country, using the reported within-county genetic correlations in 8ST and analyzing the data with 2 methods. The bending procedure was responsible, in part, for this difference, which increased the AAD value from 0.061 to 0.066 . The highest deviation from MTi genetic correlations (0.438) was for the genetic correlation between DEU traits.

The AAD between MTi and 1ST genetic correlation matrices was equal to 0.064 , with the highest deviation $(0.292)$ between DFS traits. The estimated genetic correlations by 1ST were, on average, 0.059 higher than those by MTi. The deviations between 1ST and MTi 
Table 2. The estimated genetic correlations using a multi-trait, multiple across-country evaluation analysis

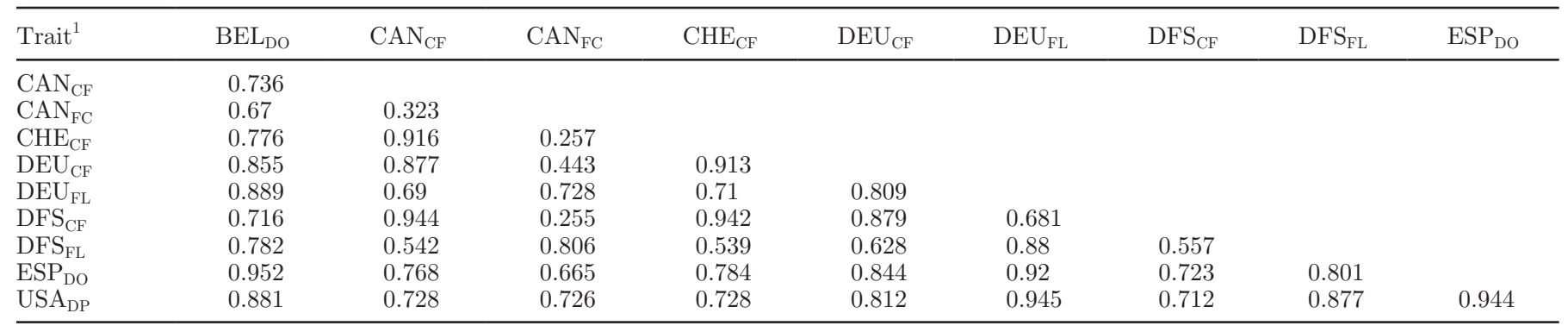

${ }^{1} \mathrm{BEL}_{\mathrm{DO}}=$ days open from Belgium; $\mathrm{CAN}_{\mathrm{CF}}=$ calving to first insemination from Canada; $\mathrm{CAN}_{\mathrm{FC}}=$ first insemination to conception from Canada; $\mathrm{CHE}_{\mathrm{CF}}=$ calving to first insemination from Switzerland; $\mathrm{DEU} \mathrm{CF}_{\mathrm{C}}=$ calving to first insemination from the joint Germany-Austria evaluation; $\mathrm{DEU}_{\mathrm{FL}}=$ first to last insemination from the joint Germany-Austria evaluation; $\mathrm{DFS}_{\mathrm{CF}}=$ calving to first insemination from the joint Nordic (Denmark-Sweden-Finland) evaluation; $\mathrm{DFS}_{\mathrm{FL}}=$ first to last insemination from the joint Nordic evaluation; $\mathrm{ESP}_{\mathrm{DO}}=$ days $_{\mathrm{Ppen}}$ from Spain; and $\mathrm{USA}_{\mathrm{DP}}=$ daughter pregnancy rate from the United States.

genetic correlations were purely due to bias. This bias was introduced to the 1ST analysis by using incorrect EDC and DPGM values for the traits from CAN and DFS.

The current study showed that if all correlations are in the same direction, the effect of bending is negligible and accounts for only a small proportion of change. However, when the correlations are a mixture of positive and negative values (i.e., their average is close to zero), the effect of bending might become substantial (Jorjani, 2006).

The main difference between the 2 methodologies (ST-MACE vs. MT-MACE) is the EDC value used both directly and indirectly (through MTi-DPGM) for the estimation of genetic correlations and prediction of international genetic merits and reliabilities. In STMACE, the country-reported $\mathrm{EDC}_{\mathrm{ST}}$ scalars are used and in $\mathrm{MTi}, \mathrm{EDC}_{\mathrm{ST}}$ scalars are converted to $\mathrm{EDC}_{\mathrm{MTi}}$ scalars, which were all slightly smaller than the cor- responding $\mathrm{EDC}_{\mathrm{ST}}$ values (98\% for CAN traits, $95 \%$ for $\mathrm{DFS}_{\mathrm{CF}}$, and $90 \%$ for $\left.\mathrm{DFS}_{\mathrm{FL}}\right)$. Considering an example of 2 traits per country, using $\mathrm{EDC}_{\mathrm{ST}}, 1$ daughter recorded for both traits would be considered as 2 daughters, each recorded for 1 trait. This type of (incorrect) information may result in greater $\mathrm{EDC}_{\mathrm{ST}}$ than $\mathrm{EDC}_{\mathrm{MTi}}$. Liu et al. (2004) compared EDC of a single-trait national repeatability animal model with EDC of a multipletrait (lactations) national random regression test-day model and showed smaller multiple-trait EDC values than single-trait EDC values. This phenomenon was explained by different definitions of standard daughter information in single- and multiple-trait models.

On average, the reliabilities by $1 \mathrm{ST}$ were greater than the reliabilities by MTi and $8 \mathrm{ST}$. The upward bias in 1ST reliabilities was due to higher (biased) EDC values used for the traits from CAN and DFS and upward bias in the estimated genetic correlations, again resulting from biased EDC values. The bias was higher for for-

Table 3. Deviations of the estimated genetic correlations by repeated single-trait, multiple across-country evaluation (ST-MACE) analyses (below diagonal) and a single ST-MACE analysis (above the diagonal) from the multi-trait, multiple across-country evaluation (MT-MACE) analysis (Table 2)

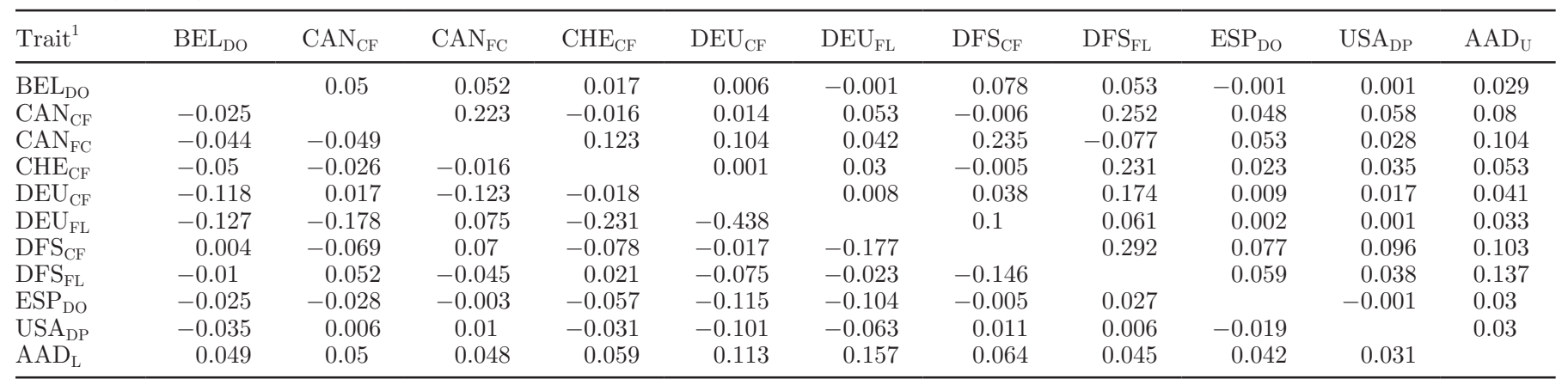

${ }^{1} \mathrm{BEL}_{\mathrm{DO}}=$ days open from Belgium; $\mathrm{CAN}_{\mathrm{CF}}=$ calving to first insemination from Canada; $\mathrm{CAN}_{\mathrm{FC}}=$ first insemination to conception from Canada: $\mathrm{CHE}_{\mathrm{CF}}=$ calving to first insemination from Switzerland; $\mathrm{DEU} \mathrm{CF}_{\mathrm{F}}=$ calving to first insemination from the joint Germany-Austria evaluation; $\mathrm{DEU}_{\mathrm{FL}}=$ first to last insemination from the joint Germany-Austria evaluation; $\mathrm{DFS}_{\mathrm{CF}}=$ calving to first insemination from the joint Nordic (Denmark-Sweden-Finland) evaluation; $\mathrm{DFS}_{\mathrm{FL}}=$ first to last insemination from the joint Nordic evaluation; $\mathrm{ESP}_{\mathrm{DO}}=$ days $_{\mathrm{D} e n}$ from Spain; $\mathrm{USA}_{\mathrm{DP}}=$ daughter pregnancy rate from the United States; $\mathrm{AAD}_{\mathrm{U}}=$ average absolute deviation for upper diagonal values; and $\mathrm{AAD}_{\mathrm{L}}=$ average absolute deviation for lower diagonal values. 
Table 4. Deviations of the reliabilities predicted by a single single-trait, multiple across-country evaluation (ST-MACE) analysis (1ST) and repeated ST-MACE analyses (8ST) from a multi-trait, multiple across-country evaluation (MT-MACE) analysis (MTi) for domestic and foreign bulls

\begin{tabular}{|c|c|c|c|c|c|}
\hline \multirow[b]{2}{*}{ Bulls } & \multirow[b]{2}{*}{ Trait $^{1}$} & \multicolumn{2}{|c|}{$\mathrm{MTi}-8 \mathrm{ST}$} & \multicolumn{2}{|c|}{$\mathrm{MTi}-1 \mathrm{ST}$} \\
\hline & & $\mathrm{n}$ & Deviation & $\mathrm{n}$ & Deviation \\
\hline \multirow[t]{11}{*}{ Domestic } & $\mathrm{BEL}_{\mathrm{DO}}$ & 395 & $1.77 \pm 2.45$ & 395 & $0.01 \pm 0.30$ \\
\hline & $\mathrm{CAN}_{\mathrm{CF}}$ & 3,895 & $0.13 \pm 0.52$ & 3,895 & $-0.96 \pm 0.80$ \\
\hline & $\mathrm{CAN}_{\mathrm{FC}}$ & 3,439 & $0.06 \pm 0.37$ & 3,439 & $-0.88 \pm 0.71$ \\
\hline & $\mathrm{CHE}_{\mathrm{CF}}$ & 609 & $0.74 \pm 1.43$ & 609 & $0.06 \pm 0.30$ \\
\hline & $\mathrm{DEU}_{\mathrm{CF}}$ & 14,672 & $2.86 \pm 1.38$ & 14,672 & $-0.09 \pm 0.33$ \\
\hline & $\mathrm{DEU}_{\mathrm{FL}}$ & 13,306 & $11.87 \pm 3.29$ & 13,741 & $-0.33 \pm 0.51$ \\
\hline & $\mathrm{DFS}_{\mathrm{CF}}$ & 8,403 & $0.82 \pm 0.79$ & 8,417 & $-3.58 \pm 1.20$ \\
\hline & $\mathrm{DFS}_{\mathrm{FL}}$ & 8,417 & $1.53 \pm 0.94$ & 8,419 & $-7.35 \pm 1.98$ \\
\hline & $\mathrm{ESP}_{\mathrm{DO}}$ & 1,221 & $0.60 \pm 1.53$ & 1,221 & $0.00 \pm 0.17$ \\
\hline & $\mathrm{USA}_{\mathrm{DP}}$ & 22,918 & $0.24 \pm 1.26$ & 22,918 & $0.00 \pm 0.16$ \\
\hline & Total & 77,275 & 2.95 & 77,726 & -1.35 \\
\hline \multirow[t]{11}{*}{ Foreign } & $\mathrm{BEL}_{\mathrm{DO}}$ & 48,775 & $7.96 \pm 6.99$ & 48,775 & $-0.54 \pm 1.00$ \\
\hline & $\mathrm{CAN}_{\mathrm{CF}}$ & 45,275 & $5.80 \pm 6.89$ & 45,275 & $-2.31 \pm 1.20$ \\
\hline & $\mathrm{CAN}_{\mathrm{FC}}$ & 45,373 & $2.76 \pm 4.39$ & 45,731 & $-1.18 \pm 2.51$ \\
\hline & $\mathrm{CHE}_{\mathrm{CF}}$ & 48,561 & $8.38 \pm 7.32$ & 48,561 & $-0.99 \pm 1.14$ \\
\hline & $\mathrm{DEU}_{\mathrm{CF}}$ & 34,498 & $7.46 \pm 4.70$ & 34,498 & $-1.67 \pm 1.55$ \\
\hline & $\mathrm{DEU}_{\mathrm{FL}}$ & 34,579 & $7.27 \pm 5.45$ & 35,429 & $-1.08 \pm 1.66$ \\
\hline & $\mathrm{DFS}_{\mathrm{CF}}$ & 40,752 & $3.95 \pm 7.16$ & 40,753 & $-4.20 \pm 2.02$ \\
\hline & $\mathrm{DFS}_{\mathrm{FL}}$ & 40,751 & $1.64 \pm 5.15$ & 40,751 & $-5.10 \pm 3.50$ \\
\hline & $\mathrm{ESP}_{\mathrm{DO}}$ & 47,949 & $7.48 \pm 7.19$ & 47,949 & $-0.63 \pm 1.09$ \\
\hline & $\mathrm{USA}_{\mathrm{DP}}$ & 26,252 & $11.84 \pm 4.42$ & 26,252 & $-1.15 \pm 1.19$ \\
\hline & Total & 412,765 & 6.27 & 413,974 & -1.86 \\
\hline
\end{tabular}

${ }^{1} \mathrm{BEL}_{\mathrm{DO}}=$ days open from Belgium; $\mathrm{CAN}_{\mathrm{CF}}=$ calving to first insemination from Canada; $\mathrm{CAN}_{\mathrm{FC}}=$ first insemination to conception from Canada; $\mathrm{CHE}_{\mathrm{CF}}=$ calving to first insemination from Switzerland; $\mathrm{DEU}_{\mathrm{CF}}$ $=$ calving to first insemination from the joint Germany-Austria evaluation; $\mathrm{DEU}_{\mathrm{FL}}=$ first to last insemination from the joint Germany-Austria evaluation; $\mathrm{DFS}_{\mathrm{CF}}=$ calving to first insemination from the joint Nordic (Denmark-Sweden-Finland) evaluation; $\mathrm{DFS}_{\mathrm{FL}}=$ first to last insemination from the joint Nordic evaluation; $\mathrm{ESP}_{\mathrm{DO}}=$ days open from Spain; and USA $\mathrm{DP}=$ daughter pregnancy rate from the United States.

eign bulls and was more obvious in the 2-trait countries (Table 4). The comparisons between 1ST and MTi were based on more observations (451 more observations for domestic bulls and 1,209 more observations for foreign bulls), because in 8ST, the bulls that had been nationally evaluated for one of the traits in the 2-trait countries did not get an international evaluation on the scale of the other trait in that country.

The reliabilities by MTi were higher compared with the reliabilities by $8 \mathrm{ST}$ (Table 4), especially for foreign bulls, and yielded 1,660 additional IPGM values, as stated in the previous paragraph. Higher reliabilities for MT-MACE compared with ST-MACE (8ST) were in accordance with the results of Mark and Sullivan (2006) on udder health traits, in which the average reliability gain was $1.58 \%$, with 2 traits from a multipletrait national evaluation (Denmark) and 9 other traits from nationally independent animal models. Using a simulated data set, Sullivan and Wilton (2001) reported an improvement in the accuracy of international genetic evaluations by MTi. In practical terms, the $8 \mathrm{ST}$ strategy is unfeasible, because it is demanding, in terms of time and computation resources, to run 8 analyses of genetic correlation estimation and 8 analyses of genetic merit prediction. The number of analyses and the time per analysis would be drastically higher on the scale of Interbull routine international genetic evaluations. The reliability gain by MTi over $8 \mathrm{ST}$ was also different from one trait to another, and from one bull to another within a trait. Mark and Sullivan (2006) reported that the reliability gain of MT-MACE over ST-MACE depends on the trait and the group of bulls in question, and young bulls gain more reliability from MT-MACE.

In some cases, the differences between IPGM from 8ST and those from MTi were greater than the differences between 1ST and MTi, both in terms of the intercept deviated from zero and the slope deviated from 1 (Table 5). The deviation of 1ST from MTi was purely due to the bias of analyzing more than one trait per country using a method that was not designed for this ability. The deviation of 8ST from MTi was due to the inability to account for the interactions that traits from the same country have with each other and also with the other countries. In this case, the evaluations by $8 \mathrm{ST}$ were not corrected for the partial correlations with the traits from the same country. Although $8 \mathrm{ST}$ was not biased, it was suboptimal because of its inability to use all available information, and it resulted in increased 
Table 5. Regression coefficients of the international predicted genetic merits (IPGM) by repeated single-trait, multiple across-country evaluation (ST-MACE) analyses (8ST) and a single ST-MACE analysis (1ST) on an multi-trait, multiple across-country evaluation (MT-MACE) analysis (MTi)

\begin{tabular}{|c|c|c|c|c|c|c|c|c|c|}
\hline Bulls & Trait $^{1}$ & \multicolumn{4}{|c|}{$\mathrm{IPGM}_{8 \mathrm{ST}}=\mathrm{a}+\mathrm{b} \times \mathrm{IPGM}_{\mathrm{MTi}}$} & \multicolumn{4}{|c|}{$\mathrm{IPGM}_{1 \mathrm{ST}}=\mathrm{a}+\mathrm{b} \times \mathrm{IPGM}_{\mathrm{MTi}}$} \\
\hline \multirow{6}{*}{ Domestic } & $\mathrm{BEL}_{\mathrm{DO}}$ & 395 & -0.021 & 0.992 & 0.988 & 395 & 0 & 0.997 & 0.998 \\
\hline & $\mathrm{CAN}_{\mathrm{FC}}$ & 3,439 & -0.007 & 1 & 0.998 & 3,439 & -0.123 & 1.001 & 0.982 \\
\hline & $\mathrm{CHE}_{\mathrm{CF}}$ & 609 & $0.653^{*}$ & $0.993^{*}$ & 0.996 & 609 & -0.158 & 1.002 & 0.999 \\
\hline & $\mathrm{DEU}_{\mathrm{CF}}$ & 14,672 & $-0.117^{* *}$ & $0.922^{* *}$ & 0.965 & 14,672 & $0.004^{* *}$ & $1.001^{* *}$ & 0.999 \\
\hline & $\mathrm{ESP}_{\mathrm{DO}}$ & 1,221 & 0.178 & 0.999 & 0.996 & 1,221 & 0.181 & 0.998 & 0.999 \\
\hline & $\mathrm{USA}_{\mathrm{DP}}$ & 22,918 & $-0.005^{* *}$ & $0.997^{* *}$ & 0.998 & 22,918 & 0 & $0.999^{* *}$ & 1 \\
\hline \multirow{5}{*}{ Foreign } & $\mathrm{BEL}_{\mathrm{DO}}$ & 48,775 & $-0.311^{* *}$ & $0.866^{* *}$ & 0.959 & 48,775 & $0.008^{* *}$ & 1 & 0.997 \\
\hline & $\mathrm{CAN}_{\mathrm{CF}}$ & 45,275 & $13.694^{* *}$ & $0.866^{* *}$ & 0.951 & 45,275 & $-2.244^{* *}$ & $1.022 * *$ & 0.991 \\
\hline & $\mathrm{CAN}_{\mathrm{FC}}$ & 45,373 & $11.927^{* *}$ & $0.882^{* *}$ & 0.941 & 45,731 & $-2.587 * *$ & $1.026^{* *}$ & 0.978 \\
\hline & $\mathrm{CHE}_{\mathrm{CF}}$ & 48,561 & $15.840^{* *}$ & $0.839^{* *}$ & 0.942 & 48,561 & $-1.119^{* *}$ & $1.012^{* *}$ & 0.993 \\
\hline & $\mathrm{USA}_{\mathrm{DP}}$ & 26,252 & $-0.025^{* *}$ & $0.815^{* *}$ & 0.961 & 26,252 & $-0.019^{* *}$ & $1.005^{* *}$ & 0.995 \\
\hline
\end{tabular}

${ }^{1} \mathrm{BEL}_{\mathrm{DO}}=$ days open from Belgium; $\mathrm{CAN}_{\mathrm{CF}}=$ calving to first insemination from Canada; $\mathrm{CAN}_{\mathrm{FC}}=$ first insemination to conception from Canada; $\mathrm{CHE}_{\mathrm{CF}}=$ calving to first insemination from Switzerland; $\mathrm{DEU} \mathrm{CF}=$ calving to first insemination from the joint Germany-Austria evaluation; $\mathrm{DEU}_{\mathrm{FL}}=$ first to last insemination from the joint Germany-Austria evaluation; $\mathrm{DFS}_{\mathrm{CF}}=$ calving to first insemination from the joint Nordic (Denmark-Sweden-Finland) evaluation; $\mathrm{DFS}_{\mathrm{FL}}=$ first to last insemination from the joint Nordic evaluation; $\mathrm{ESP}_{\mathrm{DO}}=$ days $_{\mathrm{Den}}$ from Spain; and $\mathrm{USA}_{\mathrm{DP}}=$ daughter pregnancy rate from the United States.

${ }^{2} \mathrm{H}_{0}: \mathrm{a}=0$.

${ }^{3} \mathrm{H}_{0}: \mathrm{b}=1$.

${ }^{*} P<0.05 ;{ }^{* *} P<0.01$ (significance levels are shown after Bonferroni correction for multiple dependent tests).

computing and time resources. The $\mathrm{R}^{2}$ values for $1 \mathrm{ST}$ were higher than those for 8ST. However, the IPGM values from 1ST were obviously biased.

Although the ranks of bulls in each trait obtained by different methods were highly correlated, the number of bulls in common between each 3 pairs of top 100 bulls were not high (Table 6 ). This shows that the bias in $1 \mathrm{ST}$, or making no use of the correlated information of traits from the same country in 8ST, can considerably influence the results of international evaluations for top 100 bulls in each country-trait. The rank of bulls between 1ST and MTi was closer compared with that between $8 \mathrm{ST}$ and MTi, most probably due to the simultaneous evaluation of all the traits. In addition, the number of bulls in common between the top 100 sets for 1ST and MTi was, on average, 19 bulls higher than the number of bulls in common between the top 100 sets for $8 \mathrm{ST}$ and MTi.

In this study, data from 7 countries and 10 traits were used. However, using MT-MACE for analysis of a larger number of countries and traits is quite feasible. Multi-trait MACE is able to unite multiple analyses of 1 trait per country into one analysis. However, the practical challenge arises with large number of traits and computational limitations for simultaneous estimation of all genetic correlations. For female fertility traits, there could be more than 1,000 genetic correlations to estimate. If simultaneous estimation of all genetic correlations is not possible, one option is to use data subsetting and estimate genetic correlations for a few traits at a time (e.g., separate MT-MACE analyses for rate and interval traits). In cases of combining separately estimated genetic correlations, the resulting large genetic correlation matrix may not be positive definite and may require bending. Finding a new way of combining correlation matrices or developing the current bending method (Jorjani et al., 2003) can be the next steps toward solving these issues.

\section{CONCLUSIONS}

The current method in use for international genetic evaluations (ST-MACE) does not consider nonzero residual covariances among the traits. Thus, including traits from the same country (traits that are both genetically and residually correlated) in an ST-MACE analysis would lead to bias. The estimated genetic correlations by MT-MACE were in a reasonable range, and 
Table 6. Rank correlations of all bulls in each country between different methods (below diagonal) and the number of bulls in common between the top 100 sets (upper diagonal)

\begin{tabular}{|c|c|c|c|c|}
\hline Trait $^{1}$ & Method $^{2}$ & $1 \mathrm{ST}$ & $8 \mathrm{ST}$ & $\mathrm{MTi}$ \\
\hline \multirow[t]{3}{*}{$\mathrm{BEL}_{\mathrm{DO}}$} & $1 \mathrm{ST}$ & & 52 & 88 \\
\hline & $8 \mathrm{ST}$ & 0.978 & & 59 \\
\hline & $\mathrm{MTi}$ & 0.998 & 0.981 & \\
\hline \multirow[t]{3}{*}{$\mathrm{CAN}_{\mathrm{CF}}$} & $1 \mathrm{ST}$ & & 57 & 80 \\
\hline & $8 \mathrm{ST}$ & 0.981 & & 64 \\
\hline & $\mathrm{MTi}$ & 0.995 & 0.978 & \\
\hline \multirow[t]{3}{*}{$\mathrm{CAN}_{\mathrm{FC}}$} & $1 \mathrm{ST}$ & & 69 & 83 \\
\hline & $8 \mathrm{ST}$ & 0.981 & & 75 \\
\hline & $\mathrm{MTi}$ & 0.989 & 0.975 & \\
\hline \multirow[t]{3}{*}{$\mathrm{CHE}_{\mathrm{CF}}$} & $1 \mathrm{ST}$ & & 55 & 85 \\
\hline & $8 \mathrm{ST}$ & 0.974 & & 56 \\
\hline & $\mathrm{MTi}$ & 0.997 & 0.972 & \\
\hline \multirow[t]{3}{*}{$\mathrm{DEU}_{\mathrm{CF}}$} & $1 \mathrm{ST}$ & & 59 & 90 \\
\hline & $8 \mathrm{ST}$ & 0.985 & & 65 \\
\hline & $\mathrm{MTi}$ & 0.998 & 0.987 & \\
\hline \multirow[t]{3}{*}{$\mathrm{DEU}_{\mathrm{FL}}$} & $1 \mathrm{ST}$ & & 50 & 82 \\
\hline & $8 \mathrm{ST}$ & 0.966 & & 57 \\
\hline & $\mathrm{MTi}$ & 0.998 & 0.968 & \\
\hline \multirow[t]{3}{*}{$\mathrm{DFS}_{\mathrm{CF}}$} & $1 \mathrm{ST}$ & & 66 & 84 \\
\hline & $8 \mathrm{ST}$ & 0.979 & & 70 \\
\hline & $\mathrm{MTi}$ & 0.993 & 0.981 & \\
\hline \multirow[t]{3}{*}{$\mathrm{DFS}_{\mathrm{FL}}$} & $1 \mathrm{ST}$ & & 57 & 66 \\
\hline & $8 \mathrm{ST}$ & 0.975 & & 69 \\
\hline & $\mathrm{MTi}$ & 0.985 & 0.987 & \\
\hline \multirow[t]{3}{*}{$\mathrm{ESP}_{\mathrm{DO}}$} & $1 \mathrm{ST}$ & & 53 & 87 \\
\hline & $8 \mathrm{ST}$ & 0.981 & & 61 \\
\hline & $\mathrm{MTi}$ & 0.999 & 0.984 & \\
\hline \multirow{3}{*}{$\mathrm{USA}_{\mathrm{DP}}$} & $1 \mathrm{ST}$ & & 57 & 86 \\
\hline & $8 \mathrm{ST}$ & 0.984 & & 65 \\
\hline & $\mathrm{MTi}$ & 0.999 & 0.987 & \\
\hline
\end{tabular}

${ }^{1} \mathrm{BEL}_{\mathrm{DO}}=$ days open from Belgium; $\mathrm{CAN}_{\mathrm{CF}}=$ calving to first insemination from Canada; $\mathrm{CAN}_{\mathrm{FC}}=$ first insemination to conception from Canada; $\mathrm{CHE}_{\mathrm{CF}}=$ calving to first insemination from Switzerland; $\mathrm{DEU} \mathrm{CF}_{\mathrm{CF}}$ $=$ calving to first insemination from the joint Germany-Austria evaluation; $\mathrm{DEU}_{\mathrm{FL}}=$ first to last insemination from the joint Germany-Austria evaluation; $\mathrm{DFS}_{\mathrm{CF}}=$ calving to first insemination from the joint Nordic (Denmark-Sweden-Finland) evaluation; $\mathrm{DFS}_{\mathrm{FL}}=$ first to last insemination from the joint Nordic evaluation; $\mathrm{ESP}_{\mathrm{DO}}=$ days open from Spain; and $\mathrm{USA}_{\mathrm{DP}}=$ daughter pregnancy rate from the United States.

${ }^{2} 1 \mathrm{ST}=$ single single-trait, multiple across-country evaluation (ST-MACE) analysis; 8ST = repeated ST-MACE analyses; MTi = multi-trait, multiple across-country evaluation (MT-MACE) analysis.

the differences between the estimated within-country genetic correlations and the corresponding reported values were due to different populations and models used for the estimation of genetic correlations. Both strategies of single and multiple ST-MACE analyses (avoiding the inclusion of traits from the same country in each analysis) yielded more or less the same magnitude of deviations from the MT-MACE results but for different reasons. For the single ST-MACE analysis, it was due to the bias of having traits from the same country in the analysis, and for the multiple ST-MACE analyses, it was due to the lack of benefit from having correlated traits from the same country in each analysis and using the reported within-country genetic correlation coefficients. Simultaneous analysis of traits from the same country, whether in an ST-MACE or in an MT-MACE analysis, led to reliability gain for those traits as well as the accompany traits. However, the reliability gain in the single ST-MACE analysis was associated with an upward bias. The reliability gain was different from one trait to another and from one bull to another and was generally higher for foreign bulls. Multi-trait MACE is a recommendable method for international genetic evaluations that reduces time and computational demands (compared with multiple ST-MACE analyses) and bias (compared with a single ST-MACE analysis) for having multiple traits per country.

\section{ACKNOWLEDGMENTS}

We acknowledge fruitful discussions with Peter Sullivan (CDN, Guelph, Canada), Zengting Liu (VIT, Verden, Germany), and Tomas Mark (Univ. Copenhagen, Frederiksberg, Denmark). In addition, M. A. Nilforooshan greatly acknowledges Swedish Institute (Stockholm, Sweden) for the scholarship award for a part of his PhD studies. 


\section{REFERENCES}

Banos, G., and A. Sigurdsson. 1996. Application of contemporary methods for the use of international data in national genetic evaluations. J. Dairy Sci. 79:1117-1125.

Fikse, W. F., and G. Banos. 2001. Weighting factors of sire daughter information in international genetic evaluations. J. Dairy Sci. $84: 1759-1767$.

Goddard, M. 1985. A method of comparing sires evaluated in different countries. Livest. Prod. Sci. 13:321-331.

IDF. 1981. IDF recommended procedure for international comparison of genetic merit of dairy cattle. International Dairy Federation, Doc A-64. International Dairy Federation, Brussels, Belgium.

Interbull. 2008. Interbull code of practice: Method of international evaluation. http://www.interbull.org/images/stories/chapter_5. pdf Accessed January 2010.

Jairath, L., J. C. M. Dekkers, L. R. Schaeffer, Z. Liu, E. B. Burnside, and B. Kolstad. 1998. Genetic evaluation for herd life in Canada. J. Dairy Sci. 81:550-562.

Jakobsen, J. H., and E. Hjerpe. 2006. Interbull checks of incoming data. Interbull Bull. 34:11-15.

Jorjani, H. 2006. International genetic evaluation for female fertility traits. Interbull Bull. 34:57-64.

Jorjani, H., L. Klei, and U. Emanuelson. 2003. A simple method for weighted bending of genetic (co)variance matrices. J. Dairy Sci. 86:677-679.

Klei, L., and K. A. Weigel. 1998. A method to estimate correlations among traits in different countries using data on all bulls. Interbull Bull. 17:8-14.
Liu, Z., J. Jaitner, F. Reinhardt, E. Pasman, S. Rensing, and R. Reents. 2008. Genetic evaluation of fertility traits of dairy cattle using a multiple-trait animal model. J. Dairy Sci. 91:4333-4343.

Liu, Z., F. Reinhardt, A. Bünger, and R. Reents. 2004. Derivation and calculation of approximate reliabilities and daughter yield deviations of a random regression test-day model for genetic evaluation of dairy cattle. J. Dairy Sci. 87:1896-1907.

Mark, T., and P. G. Sullivan. 2006. Multiple-trait multiple-country genetic evaluations for udder health traits. J. Dairy Sci. 89:48744885.

Schaeffer, L. R. 1994. Multiple-country comparison of dairy sires. J. Dairy Sci. 77:2671-2678.

Schaeffer, L. R. 2001. Multiple trait international bull comparisons. Livest. Prod. Sci. 69:145-153.

Sullivan, P. G., G. J. Kistemaker, J. Jakobsen, and F. Fikse. 2004 MACE weighting factors for direct and maternal EBVs from multiple-trait models. Interbull Bull. 32:53-58.

Sullivan, P. G., and J. W. Wilton. 2001. Multiple-trait MACE with a variable number of traits per country. Interbull Bull. 27:68-72.

Sullivan, P. G., J. W. Wilton, L. R. Schaeffer, G. J. Jansen, J. A. B. Robinson, and O. B. Allen. 2005. Genetic evaluation strategies for multiple traits and countries. Livest. Prod. Sci. 92:195-205.

Tarrés, J., Z. Liu, V. Ducrocq, F. Reinhardt, and R. Reents. 2007. Validation of an approximate REML algorithm for parameter estimation in a multitrait, multiple across-country evaluation model: A simulation study. J. Dairy Sci. 90:4846-4855.

Wilmink, J. B. M., A. Meijering, and B. Engel. 1986. Conversion of breeding values for milk from foreign populations. Livest. Prod. Sci. $14: 223-229$ 